\title{
BMJ Open Patterns of opioid use (codeine, morphine or meperidine) in the Canadian population over time: analysis of the Longitudinal National Population Health Survey 1994-2011
}

\author{
Mayilee Canizares, ${ }^{1} \mathrm{~J}$ Denise Power, ${ }^{1}$ Y Raja Rampersaud, ${ }^{1}$ Elizabeth M Badley ${ }^{2}$
}

To cite: Canizares M, Power JD, Rampersaud YR, et al. Patterns of opioid use (codeine, morphine or meperidine) in the Canadian population over time: analysis of the Longitudinal National Population Health Survey 1994-2011. BMJ Open 2019;9:e029613. doi:10.1136/ bmjopen-2019-029613

- Prepublication history for this paper is available online. To view these files, please visit the journal online (http://dx.doi org/10.1136/bmjopen-2019029613).

Received 1 February 2019 Revised 16 April 2019 Accepted 1 July 2019

Check for updates

(C) Author(s) (or their employer(s)) 2019. Re-use permitted under CC BY-NC. No commercial re-use. See rights and permissions. Published by BMJ.

${ }^{1}$ Arthritis Program, Krembil Research Institute, University Health Network, Toronto, Ontario, Canada

${ }^{2}$ Arthritis Community Research and Evaluation Unit, Krembil Research Institute, University Health Network, Toronto, Ontario, Canada

Correspondence to Dr Mayilee Canizares; mayilee.canizares@ uhnresearch.ca

\section{ABSTRACT}

Objective This study aimed to investigate cohort effects in selected opioids use and determine whether cohort differences were associated with changes in risk factors for use over time.

Design This study presents secondary analyses of a longitudinal survey panel of the general population that collected data biannually.

Setting Data from the Canadian Longitudinal National Population Health Survey 1994-2011.

Population This study included 12542 participants from the following birth cohorts: post-World War I (born 19151924), pre-World War II (born 1925-1934), World War II (born 1935-1944), Older Baby Boom (born 1945-1954), Younger Baby Boom (born 1955-1964), Older Generation X (born 1965-1974) and Younger Generation X (born 1975-1984).

Main outcome Responses to a single question asking about the use of codeine, morphine or meperidine in the past month (yes/no) were examined.

Results Over and above age and period effects, there were significant cohort differences in selected opioids use: each succeeding recent cohort had greater use than their predecessors (eg, Gen Xers had greater use than younger baby boomers). Selected opioids use increased significantly from 1994 to 2002, plateauing between 2002 and 2006 and then declining until 2011. After accounting for cohort and period effects, there was a decline in use of these opioids with increasing age. Although pain was significantly associated with greater selected opioids use (OR=3.63, $95 \% \mathrm{Cl} 3.39$ to 3.94), pain did not explain cohort differences. Cohort and period effects were no longer significant after adjusting for the number of chronic conditions. Cohort differences in selected opioids use mirrored cohort differences in multimorbidity. Use of these opioids was significantly associated with taking antidepressants or tranquillisers $(\mathrm{OR}=2.52,95 \% \mathrm{Cl} 2.27$ to 2.81 and $\mathrm{OR}=1.60,95 \% \mathrm{Cl} 1.46$ to 1.75 , respectively).

Conclusions The findings underscore the need to consider multimorbidity including possible psychological disorders and associated medications when prescribing opioids (codeine, morphine, meperidine), particularly for recent birth cohorts. Continued efforts to monitor prescription patterns and develop specific opioid use guidelines for multimorbidity appear warranted.
Strengths and limitations of this study

- Analyses of data from long-term longitudinal panel survey representative of the population spanning 18 years with a wide age range (10-95 years).

- Our analyses integrated changes in codeine, morphine or meperidine use with changes in risk factors over time.

- The estimates of opioid use are likely underestimates as the survey only asked about the use of specific opioids (morphine, codeine and meperidine). The study survey asked participants about opioid use regardless of source and did not ask about prescription use specifically or enquire as to the reason(s) for usage. We therefore cannot be certain of the source of opioids (eg, prescribed, prescription sharing, obtained illegally) nor can we distinguish between medical and non-medical use or definitively attribute use to specific conditions.

\section{INTRODUCTION}

Opioid use in North America and its associated harms have gained increased attention in recent years among policy makers, clinicians and the general public. Canadians are the second largest per-capita consumers of prescription opioids after the $\mathrm{USA}^{1}$; as such, better understanding of the factors associated with changes over time in opioid use is important for clinicians, policy and public health organisations, to identify population groups that are potentially at a higher risk of opioid-related harms. However, examining patterns of change over time is complex. There are three, closely related, temporal components underpinning these changes: age, period and cohort effects. Age effects are the effects of growing older independently of year of birth. Period effects are variations across time periods that simultaneously affect all age groups (eg, changes in prescription 
practices), while birth cohort effects are the results of being born at a specific point in time. Members of a birth cohort (generation) experience the same historical and social events at the same ages, and as result, they are more likely to have distinct and cohort-specific values and attitudes. ${ }^{2}$ These conditions and circumstances may uniquely shape the patterns and trajectories of opioid use among members of different cohorts.

Examining cohort differences in opioid use requires longitudinal data spanning the age difference between cohorts or the ability to combine data from a series of cross-sectional studies. Few national studies have examined cohort and period effects on opioid use in the general population. ${ }^{3-6}$ Two studies based on the US national cross-sectional surveys of the population have generally found greater prevalence of opioid use in more recent birth cohorts. ${ }^{34} \mathrm{Hu}$ et a $a \tilde{l}$ examined prescription opioid use in the US population at ages 12-34 years and similarly found that the prevalence of use increased from the 1972-1979 to the 1984-1987 birth cohorts, but in contrast to other studies, use then declined consistently among the more recent cohorts. Furthermore, none of these studies took into account the possible influence of changes in risk factors for opioid use over time in explaining the identified differences between birth cohorts. Although these studies have contributed to our understanding of changes over time in opioid use, it is not completely understood the factors underpinning these differences.

Although age has been found to be strongly related to opioid use, studies show inconsistent results. ${ }^{7-9}$ While some studies suggest higher opioid use among younger people, ${ }^{9}$ others show the opposite. ${ }^{78}$ These studies have also shown that women, those with higher education, smokers, obese individuals, those with greater depressive symptoms and greater pain had higher odds of reporting opioid use. ${ }^{7-9}$ It has also been shown that often opioid users also use antidepressants. ${ }^{10-13}$ Furthermore, studies have reported increased educational attainment and income, as well as obesity, smoking, physical activity and chronic conditions in more recent cohorts, ${ }^{14-19}$ and that the co-use of benzodiazepine and opioids in the US population has significantly increased between 1999 and $2014 .{ }^{20}$ Whether changes in these factors underlie cohort differences in opioid use remains to be explored.

Our study addresses this issue by drawing from 18 years of data from the Canadian longitudinal population health survey $(1994 / 1995$ to $2010 / 2011)$ to study the patterns of use of selected opioids in the population over time. While using panel data has the advantage that it follows the health experience of same people over time, a drawback is that the question on opioids is restricted to a list of agents chosen at the beginning of the survey in 1994/1995. A reflection of the timeframe of the survey is that it asked about use of opioids that were commonly used in the 1990s: morphine, codeine and meperidine. Whereas this could be seen to limit the relevance of the study, data from Ontario-largest province accounting for
$40 \%$ of the population of Canada-show that codeine was the most frequently prescribed opioid between 1991 and 2007 and that the prescribing of morphine also increased considerably over the same period. ${ }^{21}$ In contrast, meperidine use in the population has substantially declined since the 1990s. ${ }^{22-24}$ Furthermore, another study show that in 1991, codeine and morphine together accounted for almost all opioid-related deaths in Ontario; however, while the proportion of deaths accounted for these two agents have declined over time, the number of deaths associated with these drugs remained fairly constant between 1991 and $2015 .^{25}$ These findings coupled with research showing that the non-medical use of prescription opioids are a gateway to drugs particularly in younger generations ${ }^{26-28}$ point that examining the temporal patterns of these three agents is informative and add to the literature in this topic.

We conducted an age-period-cohort analysis to examine whether the use of these opioids differed by birth cohort after accounting for age and period effects. We also examined the contribution of changes in sociodemographic (eg, education, income) and health-related factors (eg, chronic conditions, pain, antidepressants use) to any identified age, period and cohort effects.

\section{METHODS}

\section{Study setting and population}

This paper presents secondary data analyses of the longitudinal component of the National Population Health Survey (NPHS). Conducted by Statistics Canada between 1994 and 2011, the NPHS followed up a representative sample of the Canadian population. The target population included household residents in Canada's 10 provinces in 1994/1995. More details on the NPHS sampling plan are available from Statistics Canada. ${ }^{29}$

The NPHS longitudinal sample included 17276 participants from all ages in 1994/1995 who were interviewed every 2 years. The present study included 12542 participants who were born between 1915 and 1984 (aged 10-79 years in 1994/1995) and who provided data at baseline and at least two follow-up cycles.

\section{Data sharing}

The survey is not publicly available and authorisation from Statistics Canada is required to access the data.

\section{Measures}

\section{Opioid use}

The NPHS defined use of opioids based on answers (yes/ no) to one question: 'In the past month, did you take codeine, Demerol or morphine?'

\section{Age-period-cohort}

We measured age in single year increments and defined period as the survey year. The birth cohorts examined were post-World War I (born 1915-1924), pre-World War II (born 1925-1934), World War II (born 1935-1944), 
Older Baby Boom (born 1945-1954), Younger Baby Boom (born 1955-1964), Older Generation X (born 19651974) and Younger Generation X (born 1975-1984).

\section{Risk factors}

Sociodemographic characteristics considered were sex, education (years of schooling grouped as ' $<12$ years', '12-15 years' and ' $16+$ years') and household income quartiles. Although the survey collected data on ethnicity/cultural background, the vast majority $(93.2 \%)$ of the survey participants identified themselves as white, and therefore, this variable was not included in the analysis. Lifestyle factors included were smoking status (current smoker, past smoker, never smoker); alcohol consumption (regular drinker: at least once a month, occasional drinker: less than once a month, and not currently drinking: former or never); physical activity (active vs inactive); and body mass index (BMI) (obese, overweight, normal/underweight). We also included two variables assessing health status: a variable for pain that prevents activity (no pain/ pain does not prevent activity versus pain prevents activity few/sometimes/always) and a variable for number of chronic conditions (0, 1 and 2+conditions (multimorbidity)) was derived based on the reported presence of 16 doctor-diagnosed conditions: allergies (excluding food allergies), arthritis, asthma, back problems, bronchitis, cancer, cataracts, diabetes, emphysema, glaucoma, heart conditions, high blood pressure, migraine, stroke, ulcers and urinary incontinence. Lastly, two variables related to medication use were included: use of antidepressants and tranquillisers. Similar to opioid use, these variables were ascertained through the questions, 'In the past month, did you take anti-depressants?' and 'In the past month, did you take tranquillisers such as Valium?', respectively.

\section{Statistical analysis}

A hierarchical age-period-cohort (HAPC) modelling strategy was used to understand the contribution of age, period and cohort to time changes in use of selected opioids. ${ }^{19}{ }^{30}$ In these models, observations are nested within individuals and individuals are nested within time periods. In the HAPC model, age and cohort were estimated as fixed effects, while period was estimated as a random effect. An unadjusted model with only age, period and cohort was estimated first (model 1). Linear and quadratic age terms were tested and the best transformation retained. Risk factors were then added sequentially to the fixed part of the model to examine their contributions to age, period and cohort effects: sociodemographic and lifestyle factors (model 2), chronic conditions and pain preventing activities (model 3 ) and use of tranquillisers and antidepressants (model 4). Comparing these models allowed us to examine whether changes in these risk factors over time accounted for changes in use of selected opioids. In all models, age was centred at 35 years (the median of the distribution at baseline (1994/1995)).

All models were fit using the GLIMMIX procedure from SAS/STAT version 9.4 software including incomplete cases up to the point at which they dropped out or died, and maximum likelihood estimators were used that adjust for non-response assuming the data are missing at random. ${ }^{31}$

\section{Supplementary analyses}

As it has been suggested that opioid use differs between men and women, ${ }^{32}$ analyses were stratified by sex. To examine the contribution of each individual chronic condition to cohort differences in the use of selected opioids, each of the 16 conditions were added to the final model one at a time and cohort effect estimates from these models were examined.

Almost two-fifths of eligible participants died or dropped out before the end of the study; therefore, the potential impact of attrition was also examined: models 1-4 were re-estimated by including dummy variables indicating whether the participant died or dropped out of the study. We also re-estimated the models with the sample limited to participants with complete data across the nine survey cycles.

\section{Patient involvement}

This study is based on a population survey that did not involve patients.

\section{RESULTS \\ Sample characteristics}

In 1994, there were 12542 participants contributing to three or more years of data: 1020 in the post-World War I cohort, 1377 in the pre-World War II cohort, 1591 in the World War II cohort, 2201 in the Older Baby Boom cohort, 2773 in the Younger Baby Boom cohort, 2219 in the Older Generation X cohort and 1361 Younger Generation X cohort. By 2010/2011, 27.5\% of participants dropped out and $11.8 \%$ died. Table 1 contains birth cohort characteristics at baseline. There were substantial differences across cohorts related to education, income and lifestyle factors such as smoking status, BMI, physical activity and alcohol consumption. There were also differences in the number of chronic conditions reported, as well as the use of tranquillisers and antidepressants. Over the study period, codeine, morphine or meperidine use slightly increased from $4.7 \%$ at baseline to $5.7 \%$ in 2010/2011 with similar increases across all cohorts.

\section{Changes in codeine, morphine or meperidine use: age-period- cohort effects}

Results from the unadjusted model are shown in table 2 and illustrated in figure 1A,B. There were significant age, period and cohort effects in use of selected opioids (table 2, model 1) such that comparing birth cohorts at the same age, there was a trend of greater use of these opioids from Gen Xers to the post-World War I cohort (figure 1A). In other words, members of more recent cohorts were using these opioids at earlier ages than previous cohorts. Furthermore, there was an overall 
Table 1 Birth cohort characteristics at baseline (1994/1995). Canadian National Population Health Survey, 1994-2011

\begin{tabular}{|c|c|c|c|c|c|c|}
\hline \multicolumn{7}{|c|}{ Mean (SD) or frequency (\%) } \\
\hline $\begin{array}{l}\text { Post-World } \\
\text { War I } \\
\text { (1915-1924) }\end{array}$ & $\begin{array}{l}\text { Pre-World } \\
\text { War II } \\
(1925-1934)\end{array}$ & $\begin{array}{l}\text { World War II } \\
\text { (1935-1944) }\end{array}$ & $\begin{array}{l}\text { Older } \\
\text { Baby Boom } \\
(1945-1954)\end{array}$ & $\begin{array}{l}\text { Younger } \\
\text { Baby Boom } \\
(1955-1964)\end{array}$ & $\begin{array}{l}\text { Older } \\
\text { Generation X } \\
(1965-1974)\end{array}$ & $\begin{array}{l}\text { Younger } \\
\text { Generation X } \\
(1975-1984)\end{array}$ \\
\hline $30(2.9 \%)$ & $47(3.4 \%)$ & $64(4.0 \%)$ & $108(4.9 \%)$ & $164(5.9 \%)$ & $142(6.4 \%)$ & $48(3.5 \%)$ \\
\hline
\end{tabular}

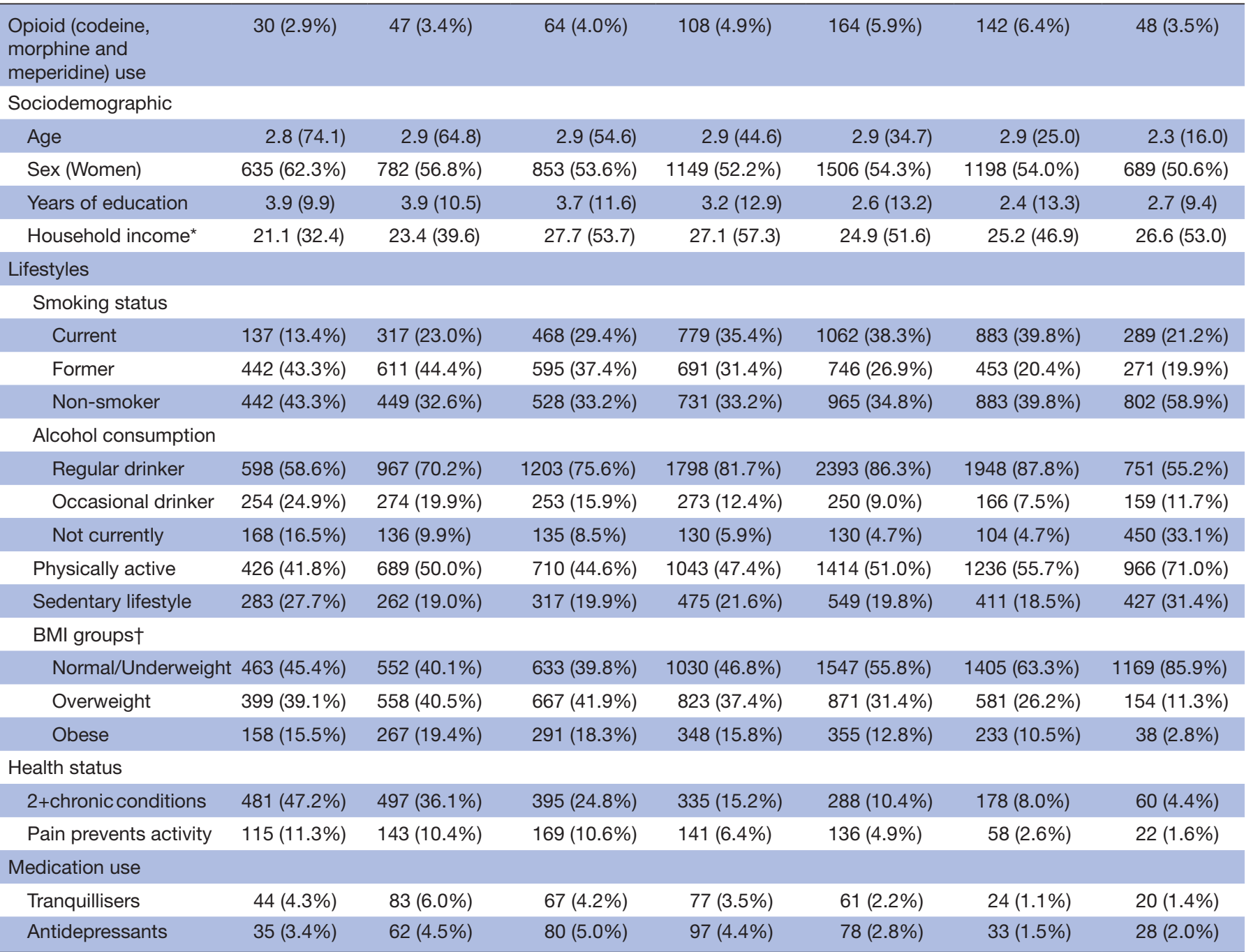

*In Canadian dollars and expressed in thousands.

†Obese ( $\geq 30.0$ ), overweight (25.0-29.9), normal/underweight (<25.0).

BMI, body mass index.

decline in use with increasing age (figure 1A). In addition to the age and cohort effects, there was a significant period effect: use of selected opioids increased steadily between 1994 and 2002, plateauing between 2002 and 2006 and declining until 2010/2011 (figure 1B).

This model was extended by including sociodemographic and lifestyle factors (table 2, model 2). The inclusion of these variables did not substantially alter estimates for age, cohort and period effects. We then added pain preventing activity to the model and, although significant, the inclusion of pain did not alter the cohort estimates (data not shown). In contrast, after adding number of chronic conditions to the model (table 2, model 3), cohort differences were no longer significant and the period effect was largely reduced (figure 1C,D, respectively). The inclusion of use of antidepressants and tranquillisers (table 2, model 4) did not affect the estimates for the age, period or cohort effects, although the effect of number of chronic conditions was attenuated.

\section{Risk factors for use of studied opioids}

The final model (table 2, model 4) shows that in addition to age, cohort and period, other independent personal risk factors for selected opioid use were being female, having higher educational attainment, being obese or being a current smoker or drinker. Health-related risk factors were having pain that prevents activity, chronic physical health conditions, taking antidepressants and tranquillisers. 
Table 2 Results from logistic hierarchical age-period-cohort models for opioid use. Canadian National Population Health Survey, 1994-2011

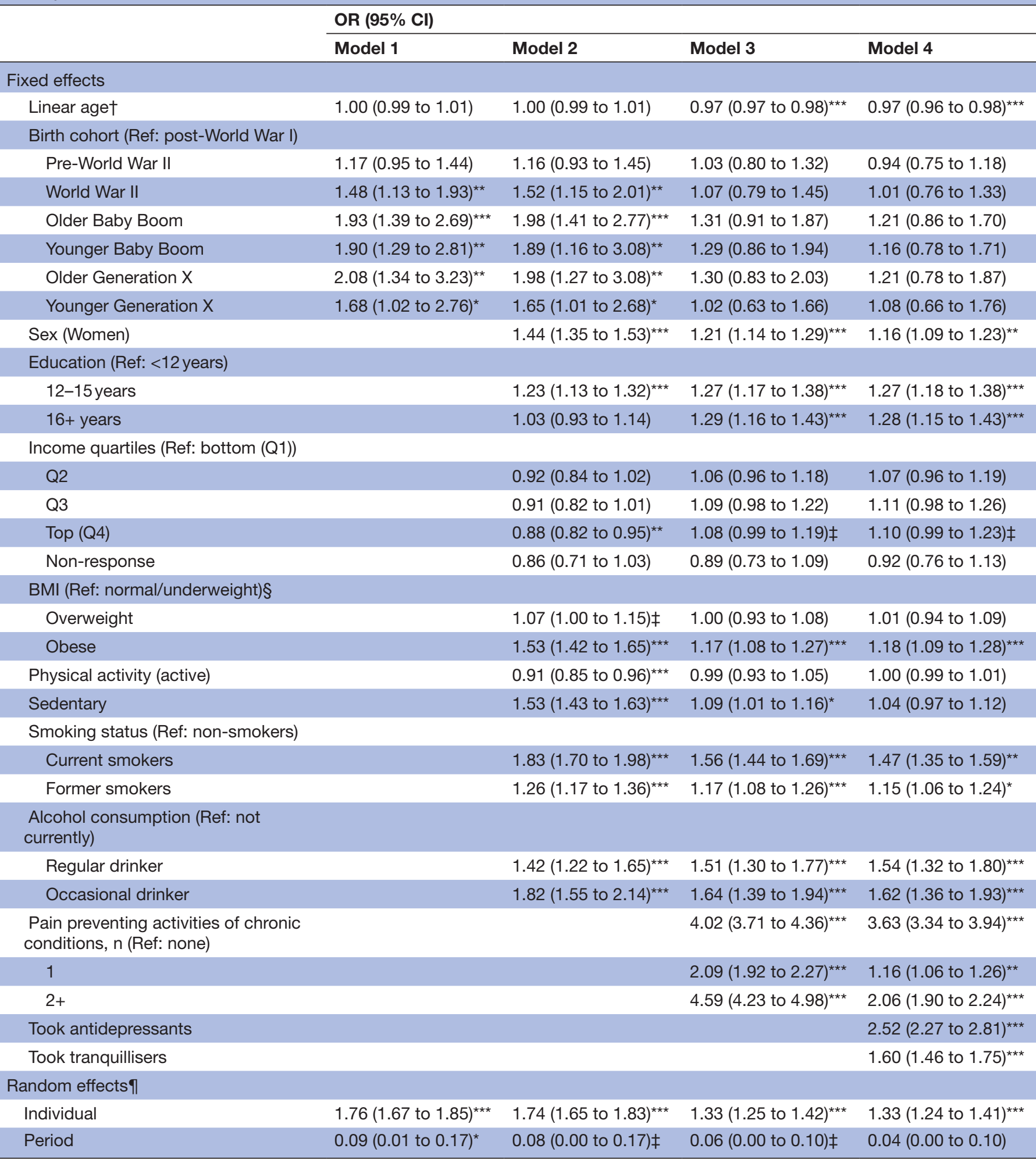

${ }^{* * *} p<0.0001,{ }^{* *} p<0.01,{ }^{*} p<0.05$.

$\dagger \mathrm{p}<0.1$.

$\ddagger$ Age was centred at 35 years. Models also included a quadratic age term.

§Obese ( $\geq 30.0)$, overweight (25.0-29.9), normal/underweight $(<25.0)$.

qEstimates are variance and $95 \% \mathrm{Cl}$.

$\mathrm{BMI}$, body mass index. 

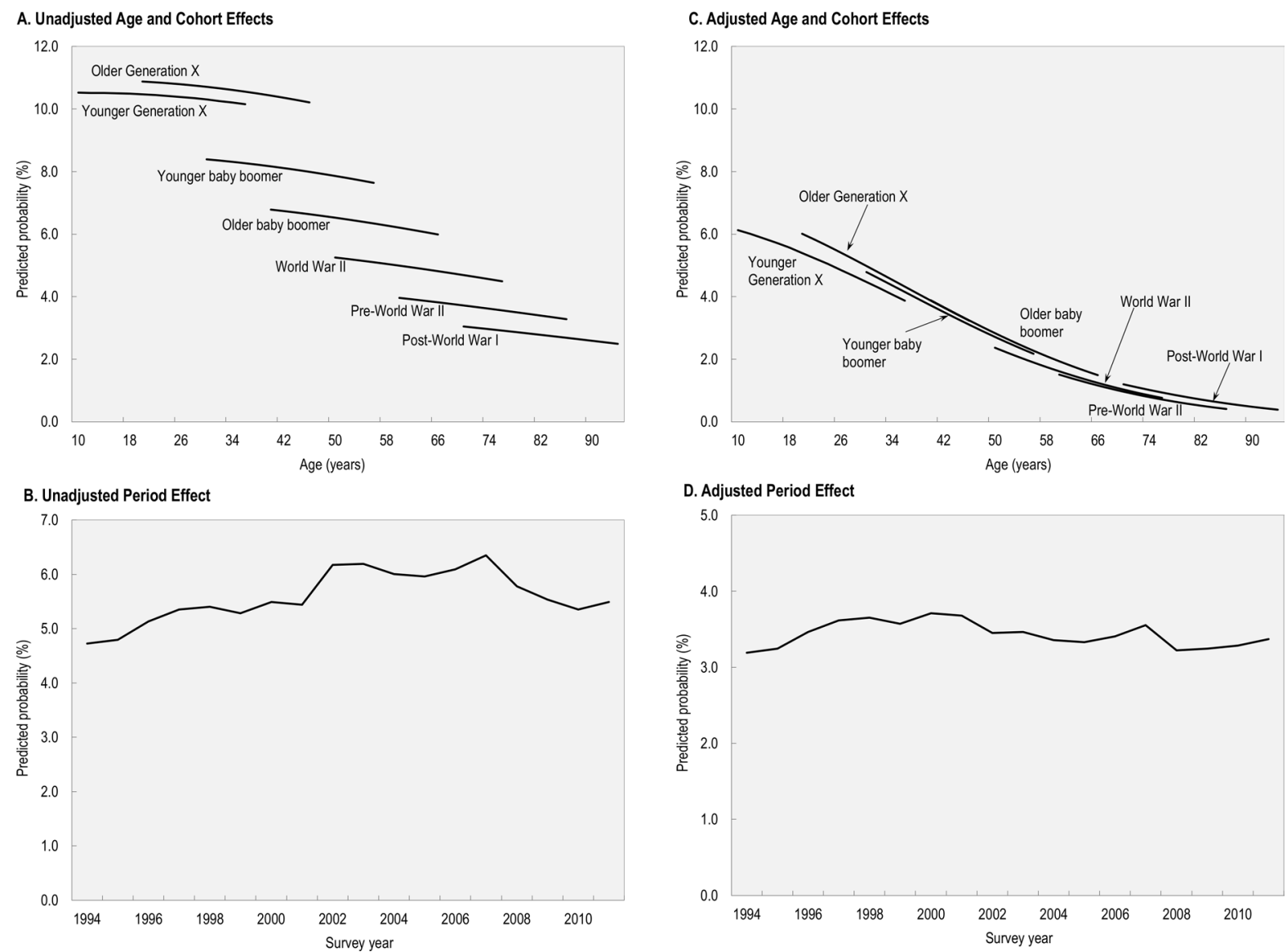

Figure 1 Age-period-cohort effects in opioid (codeine, morphine and meperidine) use. Canadian National Population Health Survey, 1994-2011. Values in (A) were obtained from the fixed effects of model 1 in table 2. Predictions are conditional on period effects. Values in (B) were obtained from the solution of the random effects of model 1 in table 2 . Predictions are conditional on age and cohort effects. Values in (C) were obtained from the fixed effects of model 5 in table 2 with covariates at their means. Values in (D) were obtained from the solution of the random effects of model 5 in table 2.

\section{Supplementary analyses}

Although women reported overall greater use of selected opioids than men, analyses stratified by sex found no significant differences in the age and cohort patterns for men and women. The findings of the analyses examining the contribution of each individual condition to cohort differences in use of selected opioids did not find that cohort differences were explained by, or attributable, to any condition in particular. Finally, the results from the analyses examining the impact of attrition (complete cases and adjusting for dropping out and death) indicated similar period and cohort effects to those obtained from the main analyses. These additional analyses did not alter our conclusions.

\section{DISCUSSION}

Using nationally representative data, this study adds to our understanding of the dynamics of morphine, codeine and meperidine use over time by identifying a strong cohort effect of greater use of these opioids in more recent birth cohorts (eg, the prevalence for Gen Xers was higher than that for younger boomers and so on). Independently of birth cohort, there was a general effect of higher use of these opioids in younger age and higher educational level. While pain preventing activity was associated with use, pain did not explain cohort differences. The cohort effect in use of these opioids parallels cohort differences in multimorbidity previously identified for this population. ${ }^{19}$ However, the cohort differences in use were not associated with any specific chronic condition in particular.

We also found a period effect: use of selected opioids increased steadily in Canada between 1994 and 2002, plateauing between 2002 and 2006 and then declining until 2011. This finding is similar to that found in other studies. ${ }^{21}{ }^{33-36}$ It has been suggested that the increase in opioid use in the 1990s is related to pharmaceutical industry opioid marketing practices to physicians during this period. ${ }^{37}$ Also over this period of time, there has been a shift from prescribing opioids primarily for severe acute or terminal pain to an increase in the use of opioids to manage any chronic painful condition. ${ }^{38-40}$

The greater morphine, codeine and meperidine use identified among those with multimorbidity is concerning, as studies have shown that the use of opioids to treat ongoing chronic conditions is associated with greater 
duration of use and higher dosages than for which the opioids were originally prescribed. ${ }^{39} 40$ These are, in turn, risk factors for opioid use disorder and overdose. ${ }^{41-43}$ Furthermore, the evidence of the efficacy of opioids for chronic non-cancer pain is limited and studies show that as well as addiction, other consequences of opioid use include increased risks of myocardial infarction, bone mineral density loss and overall mortality. ${ }^{44-47}$

In addition to having more multimorbidity, those using the three studied opioids were more likely to be taking antidepressants and tranquillisers, which is consistent with a recent US population-based study. ${ }^{20}$ It may be that reported use of antidepressants and tranquillisers are additional markers of greater multimorbidity, which is consistent with the reduction in the coefficient for multimorbidity when these drugs were added to our final model. Alternatively, this finding could represent an association between use of studied opioids and psychological issues. A number of studies focused on patients with chronic pain have reported that those with depression or other mental health disorders are more likely to be prescribed opioid therapy ${ }^{48-50}$ as well as to be prescribed a higher dose. ${ }^{51}$ It has also been reported that individuals with depression are more likely to develop clinically recognised opioid abuse and dependence. ${ }^{52}$ Likewise, the concomitant use of opioid, antidepressants and tranquillisers poses higher risks of opioid overdose and death due to overdose. ${ }^{10-13}$ As such, individuals with mental health disorders appear to represent a population for which particular caution in prescribing opioids is warranted.

The overall association of morphine, codeine or meperidine use with younger age and having higher educational attainment is in contradiction to the fact that the major clinical indications for opioids tend to increase with age and be more frequent in those with lower educational level. ${ }^{5354}$ It is possible that, at the same level of multimorbidity, the higher use of these opioids at younger ages reflects their higher non-medical use. ${ }^{455}$ Another possibility is that differences in the combinations of chronic conditions by age may underlie the age differences in opioid use. Guidelines for prescribing to older people indicate opioid use should be avoided in the presence of certain conditions to prevent adverse events. ${ }^{56}$ As a result, physicians may be more cautious about prescribing opioids to older adults. Alternatively, younger people may demand or be more willing to take these opioids than their older counterparts. The higher use of these opioids among those with higher educational level contrasts findings from other studies. ${ }^{85}{ }^{57}$ It is not clear if our findings are related to differences in physician's practice patterns or individual preferences or a combination of both. Future research is warranted to better understand the factors underlying age and educational differences in opioid use.

\section{Strength and limitations}

A major strength of this study is that it was based on one of the few available long-term longitudinal panel datasets representative of the population, with a wide age range (10-95 years), which extended over 18 years in a period of time when there were changes in codeine, morphine and meperidine use. However, the following limitations should be considered in interpreting these findings. A major limitation of the study is that the survey question asked only about three opioid agents: morphine, codeine and meperidine. At the time of the baseline survey in 1994/1995, these three agents were the most common opioids prescribed. However, since the 1990s, clinical guidelines have discouraged the prescription of meperidine, which in turn has resulted, at least partially, in a substantial declined in use of this agent in the population. ${ }^{22-24}$ This should be taken into consideration when interpreting the study findings. Another limitation is that the study survey asked participants about opioid use regardless of source and did not ask about prescription use specifically or enquire as to the reason(s) for usage. We therefore cannot be certain of the source of opioids (eg, prescribed, prescription sharing, obtained illegally) nor can we distinguish between medical and non-medical use or definitively attribute use to specific conditions. Also, our study is based on self-reported data and the biases and inaccuracies associated with it are unknown. However, in a study of older adults, overall agreement between self-reported data on opioid use and data recorded by the pharmacy was high $(93 \%) .^{58}$ Another study of patients with chronic pain comparing self-reported data on analgesic use with prescription claims data found that self-reported usage was accurate. ${ }^{59}$ These limitations notwithstanding, our study findings are informative to the literature of opioid use in the general population.

\section{CONCLUSIONS}

The dynamics of morphine, codeine or meperidine use over time are complex. Each succeeding recent generation reported greater use, and over and above this cohort effect, there was a general trend for higher use at younger ages and also in those with higher educational level. The birth cohort differences were largely explained by more multimorbidity in recent cohorts. Morphine, codeine or meperidine use was also associated with greater use of antidepressants and tranquillisers. The findings underscore the need for taking multimorbidity, including psychological disorders and associated medications, into account when prescribing opioids particularly for more recent generations. The higher opioid use in recent generations highlights the need for continued efforts to monitor opioid prescription patterns and to develop and update specific and meaningful guidelines for their appropriate use in the management of painful chronic conditions while preventing opioid misuse.

Acknowledgements We thank all the participants of Statistics Canada's National Population Health Survey.

Contributors MC was the lead author on this paper. Her contributions included study design, statistical analysis and drafting of the manuscript. JDP and YRR 
contributed to the design of the study, interpretation of results and critically revised the manuscript. EMB provided guidance on the study design, analysis and structure of the manuscript. All authors read and approved the final manuscript and are accountable for all aspects of the study.

Funding This study was partially supported by the Toronto General \& Western Hospital Foundation through the University Health Network Arthritis Program. The funding source had no role in study design, analysis or interpretation of data, writing of the manuscript or the decision to submit it for publication.

Disclaimer Access to the data was through the Statistics Canada Research Data Centres (RDC) Program, which was approved by the Social Sciences and Humanities Research Council of Canada. RDCs are operated under the provisions of the Statistics Act in accordance with all the confidentiality rules and are accessible only to researchers with approved projects. The findings and conclusions of this paper are those of the authors and do not necessarily represent the official position of Statistics Canada.

Competing interests None declared.

Patient consent for publication Not required.

Provenance and peer review Not commissioned; externally peer reviewed.

Data sharing statement Data may be obtained from a third party and are not publicly available.

Open access This is an open access article distributed in accordance with the Creative Commons Attribution Non Commercial (CC BY-NC 4.0) license, which permits others to distribute, remix, adapt, build upon this work non-commercially, and license their derivative works on different terms, provided the original work is properly cited, appropriate credit is given, any changes made indicated, and the use is non-commercial. See: http://creativecommons.org/licenses/by-nc/4.0/.

\section{REFERENCES}

1. O'Connor S, Grywacheski V, Louie K. At-a-glance - Hospitalizations and emergency department visits due to opioid poisoning in Canada. Health Promot Chronic Dis Prev Can 2018;38:244-7.

2. Ryder NB. The cohort as a concept in the study of social change. Am Sociol Rev 1965;30:843-61.

3. Martins SS, Keyes KM, Storr CL, et al. Birth-cohort trends in lifetime and past-year prescription opioid-use disorder resulting from nonmedical use: results from two national surveys. J Stud Alcohol Drugs 2010;71:480-7.

4. Miech R, Bohnert A, Heard K, et al. Increasing use of nonmedical analgesics among younger cohorts in the United States: a birth cohort effect. J Adolesc Health 2013;52:35-41.

5. Hu MC, Griesler P, Wall M, et al. Age-related patterns in nonmedical prescription opioid use and disorder in the US population at ages 12-34 from 2002 to 2014. Drug Alcohol Depend 2017;177:237-43.

6. Degenhardt L, Lynskey M, Hall W. Cohort trends in the age of initiation of drug use in Australia. Aust N Z J Public Health 2000;24:421-6.

7. Frenk SM, Lukacs SL, Gu Q. Factors associated with prescription opioid analgesic use in the US Population, 2011-2014. Pain Med 2018.

8. Parsells Kelly J, Cook SF, Kaufman DW, et al. Prevalence and characteristics of opioid use in the US adult population. Pain 2008;138:507-13.

9. Power JD, Perruccio AV, Gandhi R, et al. Factors associated with opioid use in pre-surgical knee, hip and spine osteoarthritis patients. Arthritis Care Res 2019.

10. Giummarra MJ, Gibson SJ, Allen AR, et al. Polypharmacy and chronic pain: harm exposure is not all about the opioids. Pain Med 2015;16:472-9.

11. Sun EC, Dixit A, Humphreys K, et al. Association between concurrent use of prescription opioids and benzodiazepines and overdose: retrospective analysis. BMJ 2017;356:j760.

12. Calcaterra S, Glanz J, Binswanger IA. National trends in pharmaceutical opioid related overdose deaths compared to other substance related overdose deaths: 1999-2009. Drug Alcohol Depend 2013;131:263-70.

13. Park TW, Saitz R, Ganoczy D, et al. Benzodiazepine prescribing patterns and deaths from drug overdose among US veterans receiving opioid analgesics: case-cohort study. $B M J$ 2015;350:h2698.

14. Allman-Farinelli MA, Chey T, Bauman AE, et al. Age, period and birth cohort effects on prevalence of overweight and obesity in Australian adults from 1990 to 2000. Eur J Clin Nutr 2008;62:898-907.
15. Allman-Farinelli MA, Chey $\mathrm{T}$, Merom D, et al. The effects of age, birth cohort and survey period on leisure-time physical activity by Australian adults: 1990-2005. Br J Nutr 2009;101:609-17.

16. Badley EM, Canizares M, Perruccio AV. Population-based study of changes in arthritis prevalence and arthritis risk factors over time: generational differences and the role of obesity. Arthritis Care Res 2017;69:1818-25.

17. Badley EM, Canizares M, Perruccio AV, et al. Benefits gained, benefits lost: comparing baby boomers to other generations in a longitudinal cohort study of self-rated health. Milbank $Q$ 2015;93:40-72.

18. Canizares M, Badley EM. Generational differences in patterns of physical activities over time in the Canadian population: an ageperiod-cohort analysis. BMC Public Health 2018;18:304.

19. Canizares M, Hogg-Johnson S, Gignac MAM, et al. Increasing trajectories of multimorbidity over time: birth cohort differences and the role of changes in obesity and income. J Gerontol B Psychol Sci Soc Sci 2018;73:1303-14.

20. Vozoris NT. Benzodiazepine and opioid co-usage in the US population, 1999-2014: an exploratory analysis. Sleep 2019;42.

21. Dhalla IA, Mamdani MM, Sivilotti ML, et al. Prescribing of opioid analgesics and related mortality before and after the introduction of long-acting oxycodone. CMAJ 2009;181:891-6.

22. Dobbins $\mathrm{EH}$. Where has all the meperidine gone? Nursing 2010;40:65-6.

23. Fisher JE, Zhang Y, Sketris I, et al. The effect of an educational intervention on meperidine use in Nova Scotia, Canada: a time series analysis. Pharmacoepidemiol Drug Saf 2012;21:177-83.

24. Friesen KJ, Falk J, Bugden S. The safety of meperidine prescribing in older adults: A longitudinal population-based study. BMC Geriatr 2016;16:100-00.

25. Gomes T. Latest trends in opioid-related deaths in Ontario: 1991 to 2015. 2017 https://odprn.ca/research/publications/latest-trendsin-opioid-related-deaths-in-ontario-1991-to-2015/ (Accessed Jan 2019).

26. Wall M, Cheslack-Postava K, Hu MC, et al. Nonmedical prescription opioids and pathways of drug involvement in the US: Generational differences. Drug Alcohol Depend 2018;182:103-11.

27. Bluthenthal RN, Wenger L, Chu D, et al. Drug use generations and patterns of injection drug use: Birth cohort differences among people who inject drugs in Los Angeles and San Francisco, California. Drug Alcohol Depend 2017;175:210-8.

28. Novak SP, Bluthenthal R, Wenger L, et al. Initiation of heroin and prescription opioid pain relievers by birth cohort. Am J Public Health 2016;106:298-300.

29. Statistics Canada. Information about the national population health survey. http://www23.statcan.gc.ca/imdb/p2SV.pl?Function= getSurvey\&SDDS=3225 (Accessed Jan 2019).

30. Bell A. Life-course and cohort trajectories of mental health in the UK 1991-2008--a multilevel age-period-cohort analysis. Soc Sci Med 2014;120:21-30.

31. SAS Institute Inc. The GLIMMIX Procedure (Chapter 43). SAS/STAT 9.3 User's Guide. Cary: NC: SAS Institute Inc, 2013.

32. Darnall BD, Stacey BR. Sex differences in long-term opioid use: cautionary notes for prescribing in women. Arch Intern Med 2012;172:431-2.

33. Karanges EA, Blanch B, Buckley NA, et al. Twenty-five years of prescription opioid use in Australia: a whole-of-population analysis using pharmaceutical claims. Br J Clin Pharmacol 2016;82:255-67.

34. Piper BJ, Shah DT, Simoyan OM, et al. Trends in medical use of opioids in the U.S., 2006-2016. Am J Prev Med 2018;54:652-60.

35. Han B, Compton WM, Jones CM, et al. Nonmedical prescription opioid use and use disorders among adults aged 18 through 64 years in the United States, 2003-2013. JAMA 2015;314:1468-78.

36. Guy GP, Zhang K, Bohm MK, et al. Vital signs: changes in opioid prescribing in the United States, 2006-2015. MMWR Morb Mortal Wkly Rep 2017;66:697-704.

37. Hadland SE, Cerdá M, Li Y, et al. Association of pharmaceutical industry marketing of opioid products to physicians with subsequent opioid prescribing. JAMA Intern Med 2018;178:861-3.

38. Centers for Disease Control and Prevention (CDC). Vital signs: overdoses of prescription opioid pain relievers---United States, 1999--2008. MMWR Morb Mortal Wkly Rep 2011;60:1487-92

39. Boudreau D, Von Korff M, Rutter CM, et al. Trends in long-term opioid therapy for chronic non-cancer pain. Pharmacoepidemiol Drug Saf 2009;18:1166-75.

40. Von Korff M, Korff MV, Saunders K, et al. De facto long-term opioid therapy for noncancer pain. Clin J Pain 2008;24:521-7.

41. Dunn KM, Saunders KW, Rutter CM, et al. Opioid prescriptions for chronic pain and overdose: a cohort study. Ann Intern Med 2010;152:85-92. 
42. Edlund MJ, Martin BC, Russo JE, et al. The role of opioid prescription in incident opioid abuse and dependence among individuals with chronic noncancer pain: the role of opioid prescription. Clin J Pain 2014;30:557-64.

43. Gomes T, Mamdani MM, Dhalla IA, et al. Opioid dose and drugrelated mortality in patients with nonmalignant pain. Arch Intern Med 2011:171:686-91.

44. Currow DC, Phillips J, Clark K. Using opioids in general practice for chronic non-cancer pain: an overview of current evidence. Med $J$ Aust 2016;204:305-9.

45. Cottler LB, Hu H, Smallwood BA, et al. Nonmedical opioid pain relievers and all-cause mortality: a 27-year follow-up from the epidemiologic catchment area study. Am J Public Health 2016;106:509-16.

46. Li L, Setoguchi S, Cabral H, et al. Opioid use for noncancer pain and risk of myocardial infarction amongst adults. J Intern Med 2013;273:511-26.

47. Krebs EE, Gravely A, Nugent S, et al. Effect of opioid vs nonopioid medications on pain-related function in patients with chronic back pain or hip or knee osteoarthritis pain: the SPACE Randomized Clinical Trial. JAMA 2018:319:872-82.

48. Edlund MJ, Martin BC, Devries A, et al. Trends in use of opioids for chronic noncancer pain among individuals with mental health and substance use disorders: the TROUP study. Clin J Pain 2010;26:1-8.

49. Seal KH, Shi Y, Cohen G, et al. Association of mental health disorders with prescription opioids and high-risk opioid use in US veterans of Iraq and Afghanistan. JAMA 2012;307:940-7.

50. Sullivan MD, Edlund MJ, Steffick D, et al. Regular use of prescribed opioids: association with common psychiatric disorders. Pain 2005;119:95-103.
51. Merrill JO, Von Korff M, Banta-Green CJ, et al. Prescribed opioid difficulties, depression and opioid dose among chronic opioid therapy patients. Gen Hosp Psychiatry 2012;34:581-7.

52. Edlund MJ, Steffick D, Hudson T, et al. Risk factors for clinically recognized opioid abuse and dependence among veterans using opioids for chronic non-cancer pain. Pain 2007;129:355-62.

53. Moulin DE, Clark AJ, Speechley M, et al. Chronic pain in Canada-prevalence, treatment, impact and the role of opioid analgesia. Pain Res Manag 2002;7:179-84.

54. Saastamoinen P, Leino-Arjas $\mathrm{P}$, Laaksonen M, et al. Socio-economic differences in the prevalence of acute, chronic and disabling chronic pain among ageing employees. Pain 2005;114:364-71.

55. Cicero TJ, Surratt HL, Kurtz S, et al. Patterns of prescription opioid abuse and comorbidity in an aging treatment population. $J$ Subst Abuse Treat 2012;42:87-94.

56. Pergolizzi J, Böger RH, Budd K, et al. Opioids and the management of chronic severe pain in the elderly: consensus statement of an International Expert Panel with focus on the six clinically most often used World Health Organization Step III opioids (buprenorphine, fentanyl, hydromorphone, methadone, morphine, oxycodone). Pain Pract 2008:8:287-313.

57. Martins SS, Kim JH, Chen LY, et al. Nonmedical prescription drug use among US young adults by educational attainment. Soc Psychiatry Psychiatr Epidemiol 2015;50:713-24.

58. Caskie Gl, Willis SL. Congruence of self-reported medications with pharmacy prescription records in low-income older adults. Gerontologist 2004;44:176-85.

59. Lacasse A, Ware MA, Bourgault P, et al. Accuracy of self-reported prescribed analgesic medication use: linkage between the quebec pain registry and the quebec administrative prescription claims databases. Clin J Pain 2016;32:95-102. 